\title{
INTERNACIONALIZAÇÃO DE MICRO E PEQUENAS EMPRESAS BRASILEIRAS: ANÁLISE EXPLORATÓRIA DA ATIVIDADE DE EXPORTAÇÃO
}

\author{
DUARTE, André Luís Faria ${ }^{1}$ \\ GOMES, Josir Simeone ${ }^{2}$
}

\begin{abstract}
RESUMO: O presente estudo teve por objetivo explorar pontos importantes no que se refere à evolução das exportações de micro e pequenas empresas (MPE) brasileiras, a partir de dados estatísticos disponibilizados pelo Ministério da Indústria, Comércio Exterior e Serviços, com vistas a ajudar a entender o momento atual com base na história recente do assunto. A pesquisa se caracteriza como exploratória em relação aos fins e documental e bibliográfica quanto aos meios. Foi feito levantamento, onde se procurou destacar a importância e a relevância das micro e pequenas empresas brasileiras e sua atividade de exportação para o país. Em seguida foram analisados os dados referentes ao período de 2002 a 2015. Os resultados obtidos sugerem que nos anos recentes, as MPE têm exportado menos e que, provavelmente, as iniciativas de fomento à exportação para este segmento não estão apresentando o retorno esperado.
\end{abstract}

Palavras-Chave: Comércio exterior. Microempresa. Pequena Empresa.

\section{INTERNATIONALIZATION OF MICRO AND SMALL BRAZILIAN COMPANIES: EXPLORATORY ANALYSIS OF EXPORT ACTIVITY}

SUMMARY: The purpose of this study was to explore important points regarding the evolution of exports of Brazilian micro and small enterprises, based on statistical data provided by the Ministry of Industry, Foreign Trade and Services, in order to help understand the Present moment based on the recent history of the subject. The research is characterized as exploratory in relation to the ends and documentary and bibliographical as to the means. A research was conducted to highlight the importance and relevance of micro and small Brazilian companies and their export activity to the country. Next, the data for the period from 2002 to 2015 were analyzed. The results suggest that in recent years the micro and small enterprises have been exporting less and that export promotion initiatives for this segment are probably not showing the expected return.

Keywords: Foreign trade. Micro Enterprise. Small Business.

\section{INTRODUÇÃO}

As chamadas microempresas e empresas de pequeno porte são fundamentais para o funcionamento da economia, tanto de países desenvolvidos quanto dos países em desenvolvimento (SANTOS; ALVES; ALMEIDA, 2007). Para Lunardi, Dolci e Maçada (2010), essas empresas têm sido de fundamental importância para o desenvolvimento e a manutenção da economia, realizando grande parte da atividade produtiva e sendo importante, também, para o desenvolvimento local e regional do país (INFANTE; MENDONCA; VALLE, 2014). O papel das pequenas e médias empresas (PME) no desenvolvimento econômico e tecnológico tem despertado grande interesse na literatura de gestão, para

\footnotetext{
${ }^{1}$ Bacharel em Pedagogia - Especialista em Informática Educativa - Mestre em Administração - UNESA -

Doutorando no Universidade do Grande Rio - UNIGRANRIO - Analista em C\&T na Comissão Nacional de Energia Nuclear - CNEN

${ }^{2}$ Mestre em Administração - Doutor em Administração - Professor do PPGA/UNIGRANRIO
} 
compreender como e por que as empresas que normalmente enfrentam restrições de recursos e concorrência agressiva ainda conseguem sobreviver e crescer (KISS; FERNHABER; MCDOUGALL-COVIN, 2017).

De acordo com o Serviço Brasileiro de Apoio às Micro e Pequenas Empresas (SEBRAE), durante os últimos 30 anos vem aumentando a importância das MPE no país, em função da inquestionável e relevante contribuição social e econômica desempenhada (SEBRAE, 2014). Araujo e Zilber (2013) sustentam que pequenas empresas não devem ser entendidas como grandes empresas em tamanho menor, já que têm características próprias diferentes. O universo das pequenas empresas inclui organizações com características diferentes entre si, tendo em comum o pequeno capital (SOUZA; MAZZALI, 2008).

A partir da década de 1990, a globalização dos mercados colocou as pequenas empresas brasileiras em um contexto de pressão de novas forças competitivas, no qual são necessárias novas formas de ampliar a clientela e superar concorrentes, como condições fundamentais para a sobrevivência (PELISSARI; GONZALES; VANALLE, 2011). Nesse sentido, um dos pontos que tem chamado a atenção de pesquisadores em todo o mundo é a questão da internacionalização de MPE (ZHANG et al., 2016).

\section{MICRO E PEQUENA EMPRESA EXPORTADORA}

A forma de internacionalização mais utilizada pelas PME é via exportação de produtos, pois no mundo globalizado o crescimento da economia doméstica é dependente dos mercados externos, o que gera o reconhecimento, por parte dos governos, da importância da atividade de exportação para o desenvolvimento econômico de seus países (SOUSA; LENGLER; MARTÍNEZ-LÓPEZ, 2014). Segundo Eliasson, Hansson e Lindvert (2012), vários estudos têm documentado que, dentro da mesma indústria, as empresas exportadoras têm maior produtividade do que as não exportadoras. Barney (2011) cita exemplos e ressalta que algumas empresas eram muito pequenas e muito novas quando começaram a perseguir oportunidades de negócios em mercados de vários países. De acordo com Cruz e Zouain (2008), a participação de MPE no mercado externo pode acontecer individualmente ou em conjunto com outras empresas, no modelo de consórcios de exportação.

Ruzzier, Hisrich e Antoncic (2006) sustentam que vários países, especialmente os que apresentavam déficits na balança de pagamentos, tentaram aumentar as atividades internacionais de suas PME, a fim de impulsionar o crescimento econômico, reduzir o desemprego e criar potencial de miniempresas multinacionais. No entanto, nas economias com grandes mercados internos, como EUA, Índia e Brasil, há uma tendência das empresas se sentirem desencorajadas a se internacionalizarem (CAHEN; LAHIRI; BORINI, 2016). O fato de operar em um país de dimensões continentais, com 200 milhões de habitantes e com abundância de recursos, faz com que a internacionalização não seja encarada como objetivo principal (FLORIANI; FLEURY, 2012).

No Brasil, a preocupação com as exportações e seu desempenho sempre fez parte da agenda governamental (ARBIX; SALERNO; DE NEGRI, 2005). A abertura do Brasil ao mercado internacional teve uma nova fase a partir do início dos anos 1990, a partir da abertura de seu comércio exterior e a procura por mercados externos executada como estratégia, primeiramente pelas grandes empresas, mas posteriormente, a partir de meados da década de 1990, de forma crescente pelas MPE (AMAL; FREITAG FILHO; MIRANDA, 2008). 


\section{APOIO GOVERNAMENTAL}

Historicamente, as políticas públicas brasileiras não priorizaram as MPME (SARFATI, 2013). Para Sousa e Botelho (2015), políticas direcionadas às MPE demoraram a surgir no contexto brasileiro, tendo ocorrido na primeira metade da década de 2000 a promoção de algumas medidas que objetivavam facilitar as vendas externas desse segmento.

Para La Rovere (2001), nos países desenvolvidos as políticas industriais e tecnológicas procuram dar conta das especificidades das MPMEs por meio de iniciativas que visam atender necessidades setoriais e de capacitação gerencial. Já o governo brasileiro, de acordo com Guimarães, Sacomano Neto e Vicari (2012), adota uma política de incentivo às empresas exportadoras locais, oferecendo assessoria e suporte na divulgação internacional de seus produtos, e indicando onde existem oportunidades de mercado, apesar de não conceder o necessário suporte para a realização das operações, como na área de logística e alfandegária.

Uma das ações de destaque do governo em apoio à internacionalização das MPE foi a criação, em 2003, da Agência de Promoção de Exportações e Investimentos (Apex-Brasil), que realiza ações no país e no exterior com o objetivo de adequar produtos brasileiros ao mercado internacional (ESTEVES; NOHARA, 2011). Essa agência apoia a articulação das PMEs para aumento das exportações, em parceria com a Câmara de Comércio Exterior (Camex) e com os Sebraes estaduais, incluindo a formação de consórcios de exportação, pesquisa de mercado, catálogos, feiras internacionais e promoção comercial (NARETTO; BOTELHO; MENDONÇA, 2004).

De acordo com Nogueira (2016), o plano plurianual de 2004 a 2007, formalizado pela Lei 10.933, de agosto de 2004, chamado de Plano Brasil de Todos, pela primeira vez dedica atenção efetiva às MPMEs, colocando na definição das estratégias de desenvolvimento de longo prazo, o desafio de "incentivar e fortalecer as micro, pequenas e médias empresas com o desenvolvimento da capacidade empreendedora" (Brasil, 2004). Nogueira (2016) chama a atenção para o fato de em outro desafio deste plano, "ampliar a participação do país no mercado internacional preservando os interesses nacionais", constarem como diretrizes "7. Promoção da cultura exportadora entre as pequenas e médias empresas e ampliação da sua participação nas exportações; (...) 13. Viabilização das pequenas e médias empresas no comércio exterior; 14. Estímulo à composição de consórcio de pequenas e médias empresas para a exportação" (Brasil, 2004). Neste ponto salienta-se a preocupação com a abertura das MPE ao mercado internacional.

Laval e Castro (2013) afirmam que a Lei Complementar 123 de 2006, também conhecida como Lei Geral da MPE, regulamenta o disposto na Constituição, que prevê tratamento diferenciado às micro e pequenas empresas, tendo como objetivo contribuir para o desenvolvimento e a competitividade das MPE. Essa Lei estabelece que o tratamento diferenciado deve ser regido por três instâncias: o Comitê Gestor do Simples Nacional; o Fórum Permanente das Microempresas e Empresas de Pequeno Porte; e o Comitê para Gestão da Rede Nacional para Simplificação do Registro e da Legalização de Empresas e Negócios (CGSIM) (NOGUEIRA, 2016). Outro ponto importante foi a criação, em março de 2013, da Secretaria da Micro e Pequena Empresa com status de Ministério. Essa pasta busca formular políticas de apoio às MPE, promovendo a qualificação, competitividade e incentivando as exportações de bens e serviços (LAVAL; CASTRO, 2013).

Apesar das ações aqui relacionadas, Moreira, Costa e Carpenedo (2014) consideram que as políticas governamentais de incentivo às MPE têm sido escassas e desconexas. Em relação às exportações, Alcântara et al. (2015) encontraram evidências de que as empresas precisam possuir o mínimo de condições que possibilitem o acesso e a apropriação dos incentivos, para que se beneficiem dos 
suportes governamentais à venda ao exterior.

\section{METODOLOGIA}

O estudo utilizou abordagem quantitativa, na qual problemas, opiniões e informações são traduzidos em números visando melhor entendimento (MICHEL, 2009). Quanto aos fins, a pesquisa se caracteriza como exploratória, pois tem o propósito de proporcionar familiaridade com um problema (GIL, 2008). Quanto aos meios, é considerada uma pesquisa bibliográfica e documental.

$\mathrm{Na}$ pesquisa foram utilizados dados secundários coletados na página de Estatísticas de Comércio Exterior do Ministério da Indústria, Comércio Exterior e Serviços (MDIC, 2017) disponível na internet. Os dados coletados foram tabulados em planilha eletrônica e referem-se a um período de 14 anos, de 2002 a 2015 e são apresentados de forma agrupada, com valores da média anual exportada por biênio.

\section{ANÁLISE DOS DADOS}

O dado coletado mais abrangente refere-se às exportações brasileiras totais e das MPE. Pode-se observar que o percentual de exportação das MPE tem diminuído ao longo desses anos. No biênio 200203 este setor respondia por 2,30\% das exportações brasileira, tendo recuado, chegando a $0,73 \%$ no biênio 2012-13, apresentando alguma recuperação em 2014-2015, aumentando para o patamar de 0,97\% do total de exportações (Tabela 1).

Tabela 1 - Exportações brasileiras

\begin{tabular}{c|r|r|r|r|c}
\hline Biênio & Total exportado & Microempresa & $\begin{array}{c}\text { Pequena } \\
\text { empresa }\end{array}$ & \multicolumn{1}{c}{ MPE } & $\begin{array}{c}\text { \% MPE / } \\
\text { exportações }\end{array}$ \\
\hline $2002-2003$ & 66.722 .962 .531 & 194.178 .106 & 1.340 .708 .588 & 1.534 .886 .693 & $2,30 \%$ \\
\hline $2004-2005$ & 107.502 .211 .621 & 292.907 .378 & 2.145 .244 .139 & 2.438 .151 .517 & $2,27 \%$ \\
\hline $2006-2007$ & 149.228 .271 .181 & 334.277 .143 & 2.356 .829 .336 & 2.691 .106 .479 & $1,80 \%$ \\
\hline $2008-2009$ & 175.468 .592 .857 & 259.031 .996 & 1.554 .718 .728 & 1.813 .750 .723 & $1,03 \%$ \\
\hline $2010-2011$ & 228.977 .430 .052 & 228.138 .383 & 1.770 .289 .716 & 1.998 .428 .099 & $0,87 \%$ \\
\hline $2012-2013$ & 242.379 .212 .518 & 195.013 .030 & 1.581 .261 .041 & 1.776 .274 .071 & $0,73 \%$ \\
\hline $2014-2015$ & 208.117 .604 .708 & 223.170 .691 & 1.789 .686 .039 & 2.012 .856 .730 & $0,97 \%$ \\
\hline
\end{tabular}

Fonte: Elaboração própria com base nos dados do MDIC (2017)

Pode-se observar que as exportações das MPE aumentaram até o biênio 2006-2007, embora em ritmo menor que as exportações totais. No biênio 2008-09 houve acentuada queda, mantendo esse patamar até 2014-15. Em relação ao total de exportação, o percentual das MPE apresentou recuperação parcial, já que o total de exportação no biênio 2014-15 diminuiu e o total das MPE aumentou, ficando próximo de $1 \%$ do total (Gráfico 1). 
Gráfico 1 - Exportações brasileiras totais e das MPE.

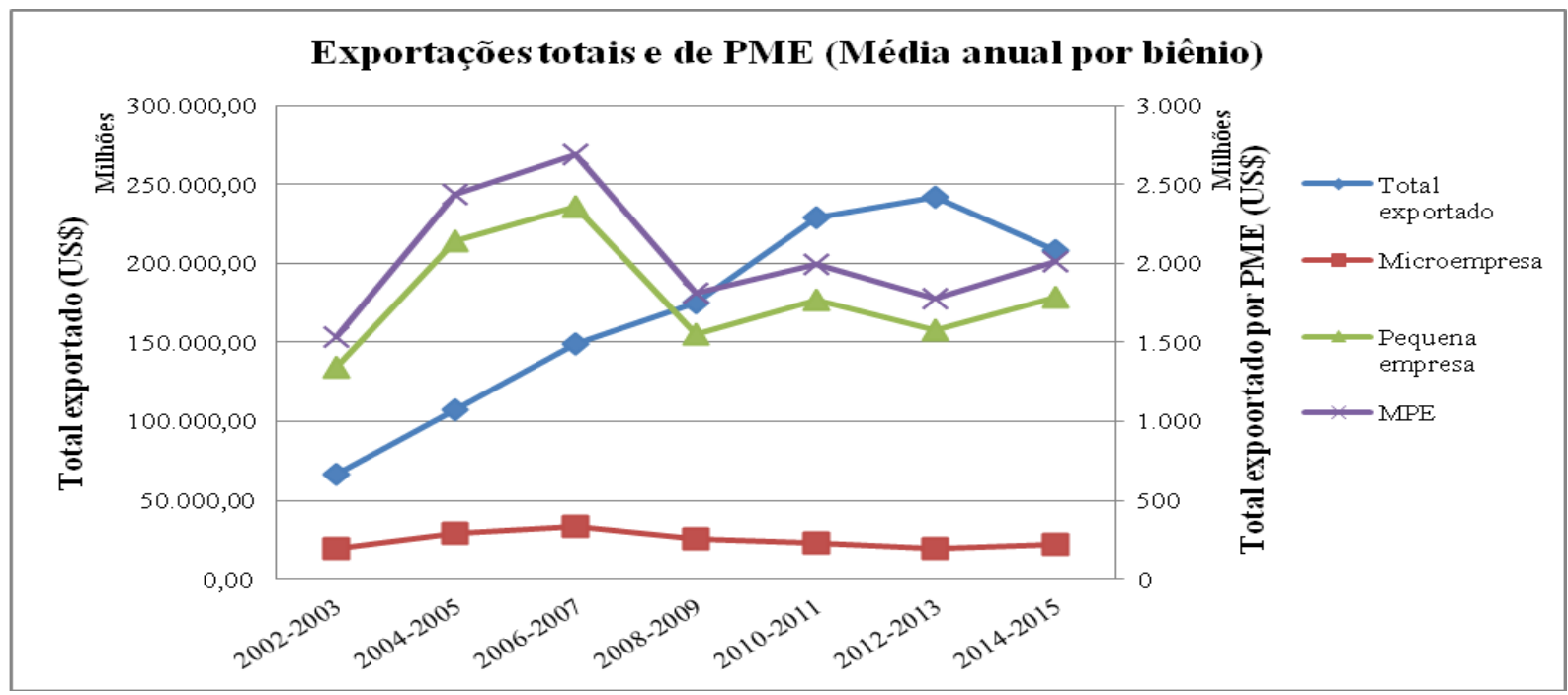

Fonte: Elaboração própria com base nos dados do MDIC (2017)

Ao se observar esses números percebe-se que desde 2008-09, os valores das exportações de MPE oscilaram entre US\$ 1,7 e US\$ 2.0 bilhões, não chegando ao patamar anterior acima de US\$ 2,5 bilhões.

Em relação aos principais destinos, é notável que durante todo o período estudado, os quatro principais destinos das exportações brasileiras tenham se mantido os mesmos. China, EUA, Argentina e Holanda, apesar de variarem de posição entre si ao longo dos anos, têm se mantido como os quatro principais destinos dos produtos brasileiros. Vale ressaltar que os EUA, no biênio 2002-03, respondia por $24 \%$ das exportações do Brasil, ou seja, quase um quarto do que era exportado ia para os EUA. No último biênio estudado, este índice está em pouco mais de $12 \%$. Ressalta-se também que ao longo do período estudado, esses quatro países representaram entre $36 \%$ e $43 \%$ do total de exportações brasileiras (Tabela 2).

Tabela 2 - Principais destinos das exportações brasileiras

\begin{tabular}{c|c|c|c|c|c|c|c}
\hline & $\mathbf{2 0 0 2 - 0 3}$ & $\mathbf{2 0 0 4 - 0 5}$ & $\mathbf{2 0 0 6 - 0 7}$ & $\mathbf{2 0 0 8 - 0 9}$ & $\mathbf{2 0 1 0 - 1 1}$ & $\mathbf{2 0 1 2 - 1 3}$ & $\mathbf{2 0 1 4 - 1 5}$ \\
\hline \multicolumn{1}{c|}{ Total } & 66.722 .962 .531 & 107.502 .211 .621 & 149.228 .271 .181 & 175.468 .592 .857 & 228.977 .430 .052 & 242.379 .212 .518 & 208.117 .604 .708 \\
\hline China & $5,3 \%$ & $5,7 \%$ & $6,4 \%$ & $10,4 \%$ & $16,4 \%$ & $18,0 \%$ & $18,3 \%$ \\
\hline EUA & $24,0 \%$ & $19,8 \%$ & $16,6 \%$ & $12,3 \%$ & $9,9 \%$ & $10,6 \%$ & $12,3 \%$ \\
\hline Argentina & $5,2 \%$ & $8,0 \%$ & $8,8 \%$ & $8,7 \%$ & $9,0 \%$ & $7,8 \%$ & $6,5 \%$ \\
\hline Holanda & $5,6 \%$ & $5,2 \%$ & $4,9 \%$ & $5,3 \%$ & $5,2 \%$ & $6,7 \%$ & $5,5 \%$ \\
\hline Soma $(\%)$ & $40,0 \%$ & $38,7 \%$ & $36,7 \%$ & $36,7 \%$ & $40,5 \%$ & $43,0 \%$ & $42,6 \%$ \\
\hline
\end{tabular}

Fonte: Elaboração própria com base nos dados do MDIC (2017)

Em relação à China, é notável o crescimento das exportações durante o período estudado. Do biênio 2002-03 para o de 2014-15, o volume cresceu mais de 10 vezes. A partir do biênio 2010-11, esse país assumiu o primeiro lugar como destino às exportações com folga, representando no biênio 2014-15, quase $20 \%$ das exportações brasileiras (Gráfico 2). 
Gráfico 2 - Principais destinos das exportações brasileiras.



Fonte: Elaboração própria com base nos dados do MDIC (2017)

Se no total das exportações brasileiras há certa homogeneidade em relação aos principais destinos, o mesmo não acontece quando se analisam as exportações das MPE. Nos últimos 3 biênios, os quatro principais destinos se mantiveram, sendo EUA, Paraguai, Argentina e China. No entanto, nos outros quatro biênios do período estudado, outros países figuraram entre os quatro primeiros destinos, como Chile, Espanha, Itália e Alemanha. Os quatro principais destinos representaram, ao longo do período, entre $35,0 \%$ e $37,5 \%$, o que mostra menor concentração, quando se compara ao total de exportações brasileiras.

Vale ressaltar que no biênio 2002-03 havia apenas dois países sul-americanos entre os dez principais destinos. Nos biênios 2004-05 e 2006-07 esse número aumentou para três, nos biênios 2008-09 e 2010-11 passou para cinco, no biênio 2012-13 chegou a seis, e no último biênio estudado voltou a cinco. Tais números evidenciam o aumento substancial de exportações das MPE brasileiras para países sulamericanos (Tabela 3).

Tabela 3 - Principais destinos das exportações de MPE brasileiras

\begin{tabular}{|c|c|c|c|c|c|c|c|c|c|c|c|c|c|}
\hline \multicolumn{2}{|c|}{ 2002-03 } & \multicolumn{2}{|c|}{ 2004-05 } & \multicolumn{2}{|c|}{ 2006-07 } & \multicolumn{2}{|c|}{ 2008-09 } & \multicolumn{2}{|c|}{ 2010-11 } & \multicolumn{2}{|c|}{ 2012-13 } & \multicolumn{2}{|c|}{ 2014-15 } \\
\hline \multicolumn{2}{|c|}{1.534 .886 .693} & \multicolumn{2}{|c|}{ 2.438.151.517 } & \multicolumn{2}{|c|}{ 2.691.106.479 } & \multicolumn{2}{|c|}{1.813 .750 .723} & \multicolumn{2}{|c|}{ 1.998.428.099 } & \multicolumn{2}{|c|}{1.776 .274 .071} & \multicolumn{2}{|c|}{2.012 .856 .730} \\
\hline País & $\%$ & País & $\%$ & País & $\%$ & País & $\%$ & País & $\%$ & País & $\%$ & País & $\%$ \\
\hline EUA & 23,0 & EUA & 21,2 & EUA & 20,3 & EUA & 16,7 & EUA & 15,9 & EUA & 15,7 & EUA & 18,3 \\
\hline Argentina & 5,8 & Argentina & 7,9 & Argentina & 7,7 & Argentina & 9,7 & Argentina & 9,7 & Argentina & 8,1 & Paraguai & 7,1 \\
\hline Itália & 4,7 & Espanha & 4,1 & Paraguai & 4,5 & Paraguai & 4,9 & Paraguai & 6,8 & Paraguai & 7,0 & Argentina & 6,9 \\
\hline \multirow[t]{2}{*}{ Alemanha } & 4,0 & China & 4,0 & Espanha & 3,9 & Chile & 3,8 & China & 4,2 & China & 4,4 & China & 4,0 \\
\hline & 37,4 & & 37,2 & & 36,4 & & 35,1 & & 36,6 & & 35,2 & & 36,4 \\
\hline Espanha & 3,9 & Itália & 3,9 & Holanda & 3,7 & China & 3,6 & Uruguai & 3,8 & Uruguai & 4,3 & Uruguai & 3,5 \\
\hline Paraguai & 3,9 & Alemanha & 3,6 & China & 3,7 & Alemanha & 3,5 & Alemanha & 3,7 & Chile & 4,0 & Chile & 3,1 \\
\hline China & 3,6 & Paraguai & 3,6 & Itália & 3,5 & Itália & 3,4 & Chile & 3,4 & Alemanha & 3,3 & Alemanha & 3,1 \\
\hline Holanda & 3,5 & Holanda & 3,4 & França & 3,1 & Uruguai & 3,4 & Holanda & 3,0 & Venezuela & 3,0 & Holanda & 3,0 \\
\hline Reino Unido & 3,5 & Chile & 3,4 & Alemanha & 3,0 & Venezuela & 3,4 & Venezuela & 2,8 & Bolívia & 2,8 & Bolívia & 3,0 \\
\hline Japão & 3,5 & $\begin{array}{l}\text { Reino } \\
\text { Unido }\end{array}$ & 3,2 & Uruguai & 3,0 & Holanda & 2,9 & França & 2,7 & Angola & 2,7 & Itália & 2,8 \\
\hline
\end{tabular}

Fonte: Elaboração própria com base nos dados do MDIC (2017) 
Durante todo o período estudado, os EUA figuraram na primeira posição e a Argentina, com exceção do último biênio, figurou na segunda (Gráfico 3).

Gráfico 3 - Principais destinos das exportações de MPE brasileiras.

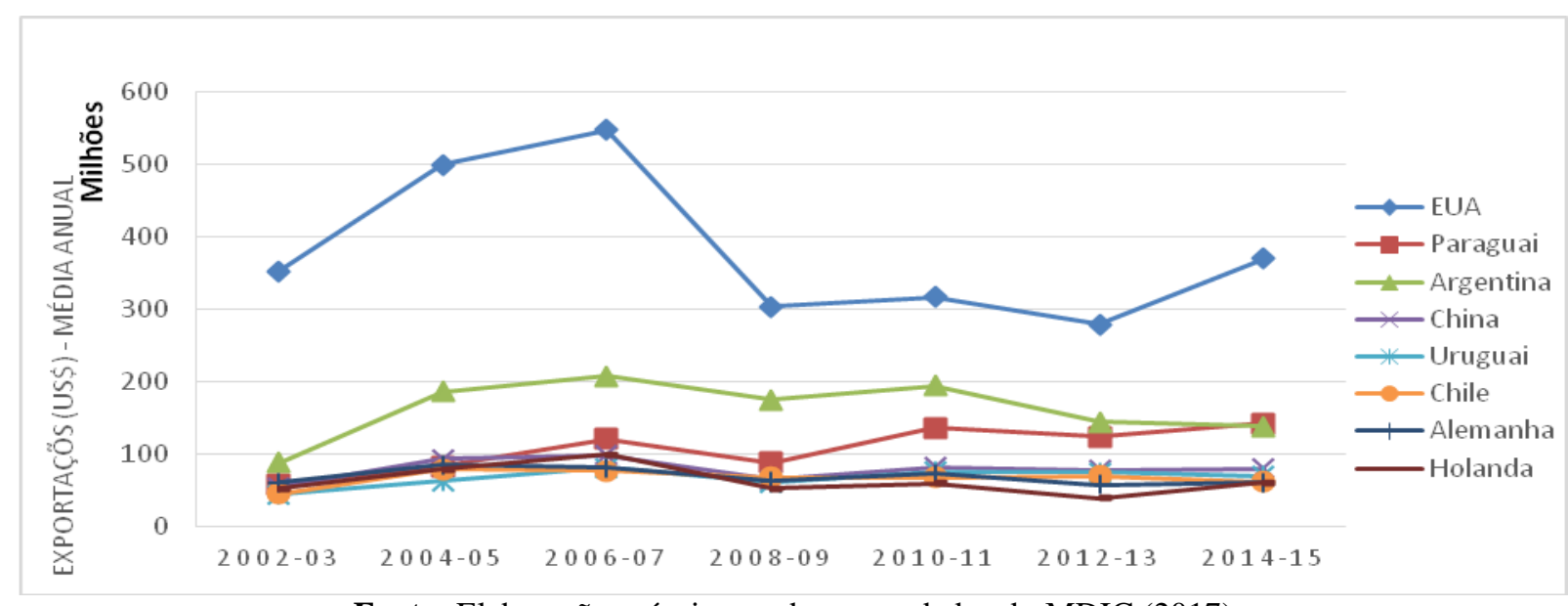

Fonte: Elaboração própria com base nos dados do MDIC (2017)

Em relação à unidade da federação onde fica a sede da empresa exportadora, os estados de São Paulo, Minas Gerais, Rio de Janeiro, Paraná e Rio Grande do Sul aparecem nas cinco primeiras posições durante todo o período estudado. No entanto, a participação desses cinco estados no total exportado tem diminuído ao longo do período. Todos os sete estados das regiões Sudeste e Sul aparecem entre os nove primeiros em todos os biênios e os dez primeiros estados respondem por mais de $90 \%$ das exportações brasileiras (Tabela 4).

Tabela 4 - Principais Estados sede das empresas exportadoras

\begin{tabular}{c|r|r|r|r|r|r|r|r|r|r|r|r|r|r}
\hline \multicolumn{2}{c|}{$\mathbf{2 0 0 2 - 0 3}$} & \multicolumn{2}{c|}{$\mathbf{2 0 0 4 - 0 5}$} & \multicolumn{2}{|c|}{$\mathbf{2 0 0 6 - 0 7}$} & \multicolumn{2}{c|}{$\mathbf{2 0 0 8 - 0 9}$} & \multicolumn{2}{|c|}{$\mathbf{2 0 1 0 - 1 1}$} & \multicolumn{2}{|c|}{$\mathbf{2 0 1 2 - 1 3}$} & \multicolumn{2}{|c|}{$\mathbf{2 0 1 4 - 1 5}$} \\
\hline SP & $37,2 \%$ & SP & $33,7 \%$ & SP & $35,7 \%$ & SP & $31,8 \%$ & SP & $26,6 \%$ & SP & $26,5 \%$ & SP & $26,3 \%$ \\
\hline RS & $10,3 \%$ & MG & $10,6 \%$ & MG & $10,9 \%$ & MG & $11,8 \%$ & MG & $15,0 \%$ & MG & $12,8 \%$ & MG & $12,1 \%$ \\
\hline PR & $8,8 \%$ & RS & $9,4 \%$ & RJ & $8,9 \%$ & RJ & $9,9 \%$ & RJ & $11,9 \%$ & RJ & $11,7 \%$ & RJ & $10,9 \%$ \\
\hline MG & $8,7 \%$ & PR & $9,0 \%$ & RS & $8,3 \%$ & RS & $8,9 \%$ & PR & $7,7 \%$ & RS & $8,6 \%$ & PR & $8,2 \%$ \\
\hline RJ & $7,4 \%$ & RJ & $7,5 \%$ & PR & $7,9 \%$ & PR & $8,2 \%$ & RS & $7,3 \%$ & PR & $8,1 \%$ & RS & $8,2 \%$ \\
\hline Acumul. & $72,3 \%$ & & $70,2 \%$ & & $71,8 \%$ & & $70,6 \%$ & & $68,6 \%$ & & $67,7 \%$ & & $65,8 \%$ \\
\hline SC & $6,0 \%$ & SC & $5,3 \%$ & SC & $5,2 \%$ & PA & $5,3 \%$ & PA & $7,0 \%$ & PA & $6,3 \%$ & PA & $5,9 \%$ \\
\hline ES & $5,3 \%$ & BA & $4,6 \%$ & BA & $4,9 \%$ & BA & $4,7 \%$ & ES & $6,1 \%$ & ES & $4,8 \%$ & ES & $5,5 \%$ \\
\hline BA & $4,2 \%$ & ES & $4,6 \%$ & PA & $4,8 \%$ & SC & $5,1 \%$ & SC & $4,4 \%$ & SC & $4,6 \%$ & MT & $5,3 \%$ \\
\hline PA & $3,6 \%$ & PA & $3,9 \%$ & ES & $4,7 \%$ & ES & $4,5 \%$ & BA & $4,2 \%$ & MT & $4,5 \%$ & SC & $4,8 \%$ \\
\hline AM & $1,7 \%$ & MT & $2,8 \%$ & MT & $2,0 \%$ & MT & $3,1 \%$ & MT & $3,1 \%$ & BA & $4,3 \%$ & BA & $3,9 \%$ \\
\hline Acumul. & $93,2 \%$ & & $91,4 \%$ & & $93,4 \%$ & & $93,2 \%$ & & $93,2 \%$ & & $92,3 \%$ & & $91,2 \%$ \\
\hline Regiões & & & & & & & & & & & & & \\
\hline SE & $58,6 \%$ & & $56,3 \%$ & & $60,2 \%$ & & $58,0 \%$ & & $59,6 \%$ & & $55,8 \%$ & & $54,8 \%$ \\
\hline S & $25,1 \%$ & & $23,7 \%$ & & $21,5 \%$ & & $22,1 \%$ & & $19,4 \%$ & & $21,4 \%$ & & $21,3 \%$ \\
\hline N, NE, CO & $16,3 \%$ & & $20,0 \%$ & & $18,3 \%$ & & $19,9 \%$ & & $21,0 \%$ & & $22,8 \%$ & & $23,9 \%$ \\
\hline
\end{tabular}

Fonte: Elaboração própria com base nos dados do MDIC (2017)

O estado de São Paulo aparece em primeiro lugar durante todo o período estudado, mas tem diminuído sua participação ao longo do tempo. No biênio 2002-03, 37,2\% das exportações partiram de empresas sediadas nesse estado. No biênio 2014-15 esse número diminuiu para 26,3\%. Minas Gerais aparece em segundo lugar desde o biênio 2004-05 e o Rio de Janeiro em terceiro lugar desde 
2006-07 (Gráfico 4).

Gráfico 4 - Principais Estados sede das empresas exportadoras.

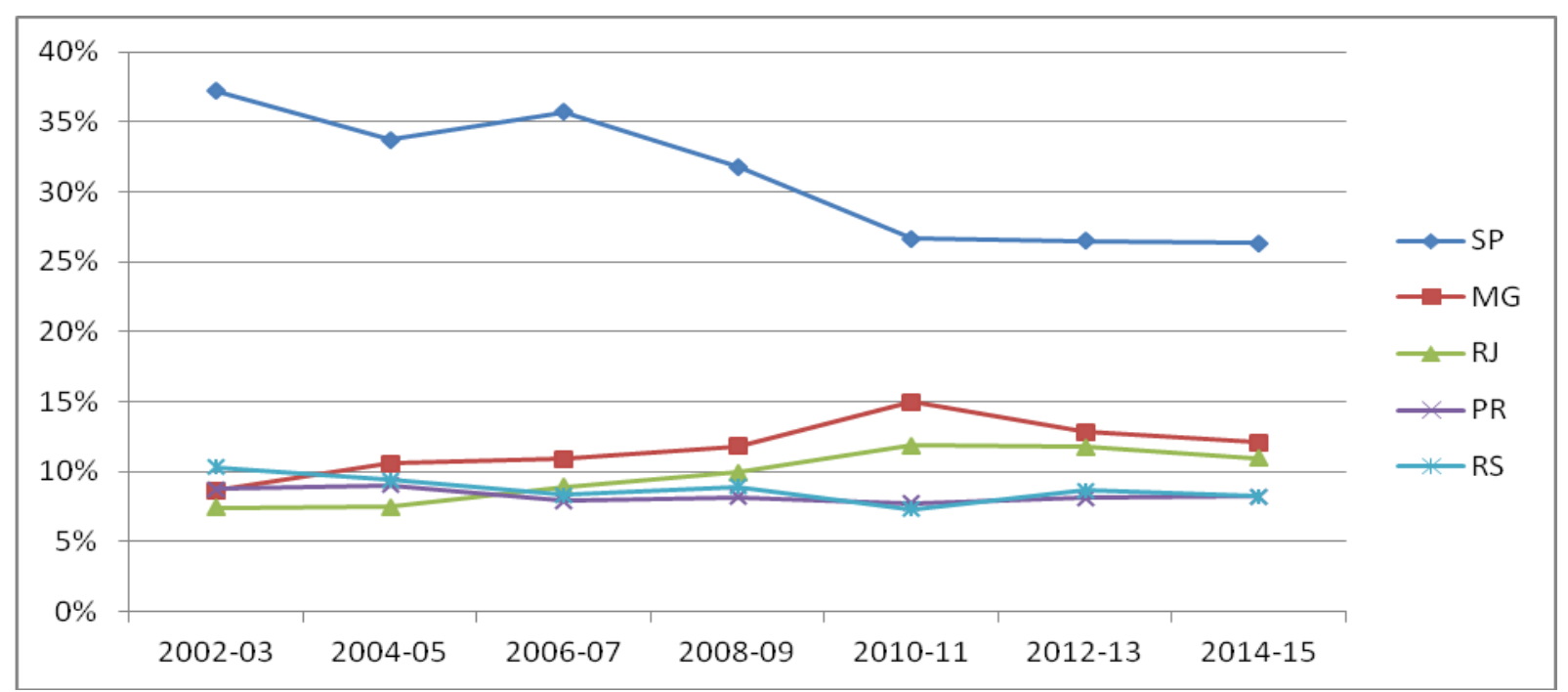

Fonte: Elaboração própria com base nos dados do MDIC (2017)

A análise dos estados que sediam as PMEs exportadoras apresenta um quadro diferente, especialmente em relação aos estados da região Sul. O percentual do valor exportado por MPE sediadas nessa região fica em torno de $30 \%$, percentual bem acima da média do total de exportações. São Paulo também figura em primeiro lugar, mantendo uma regularidade acima de $30 \%$ do valor exportado. O que pode ser considerado uma surpresa é o estado do Rio de Janeiro aparecer, durante o período pesquisado, oscilando entre o sétimo e o oitavo lugar (Tabela 5).

Tabela 5 - Principais Estados sede das MPE exportadoras

\begin{tabular}{c|c|c|c|c|c|c|c|c|c|c|c|c|c}
\hline \multicolumn{2}{c|}{$\mathbf{2 0 0 2 - 0 3}$} & \multicolumn{2}{|c|}{$\mathbf{2 0 0 4 - 0 5}$} & \multicolumn{2}{|c|}{$\mathbf{2 0 0 6 - 0 7}$} & \multicolumn{2}{c|}{$\mathbf{2 0 0 8 - 0 9}$} & \multicolumn{2}{c|}{$\mathbf{2 0 1 0 - 1 1}$} & \multicolumn{2}{c|}{$\mathbf{2 0 1 2 - 1 3}$} & \multicolumn{2}{c}{$\mathbf{2 0 1 4 - 1 5}$} \\
\hline SP & $31,3 \%$ & SP & $30,5 \%$ & SP & $32,3 \%$ & SP & $35,6 \%$ & SP & $35,6 \%$ & SP & $35,4 \%$ & SP & $33,8 \%$ \\
\hline RS & $11,3 \%$ & RS & $10,6 \%$ & RS & $12,0 \%$ & RS & $12,9 \%$ & RS & $13,4 \%$ & RS & $14,2 \%$ & RS & $12,2 \%$ \\
\hline PR & $11,2 \%$ & PR & $10,4 \%$ & PR & $11,3 \%$ & PR & $9,8 \%$ & PR & $10,6 \%$ & PR & $11,2 \%$ & PR & $11,1 \%$ \\
\hline SC & $8,6 \%$ & SC & $8,7 \%$ & ES & $6,8 \%$ & MG & $8,1 \%$ & MG & $8,1 \%$ & MG & $8,7 \%$ & MG & $8,5 \%$ \\
\hline MG & $6,9 \%$ & MG & $6,9 \%$ & SC & $6,7 \%$ & SC & $6,6 \%$ & SC & $5,9 \%$ & SC & $6,0 \%$ & ES & $6,5 \%$ \\
\hline PA & $5,3 \%$ & ES & $5,7 \%$ & MG & $6,5 \%$ & ES & $6,5 \%$ & ES & $5,9 \%$ & ES & $5,0 \%$ & SC & $6,0 \%$ \\
\hline ES & $5,0 \%$ & PA & $4,6 \%$ & PA & $5,2 \%$ & RJ & $4,0 \%$ & PA & $4,2 \%$ & PA & $4,6 \%$ & RJ & $4,1 \%$ \\
\hline RJ & $4,4 \%$ & RJ & $3,0 \%$ & RJ & $4,6 \%$ & PA & $3,9 \%$ & RJ & $4,0 \%$ & RJ & $3,6 \%$ & PA & $3,9 \%$ \\
\hline BA & $2,8 \%$ & MT & $2,8 \%$ & MT & $2,6 \%$ & MT & $2,1 \%$ & BA & $1,9 \%$ & BA & $2,2 \%$ & BA & $2,8 \%$ \\
\hline MT & $2,7 \%$ & BA & $2,6 \%$ & BA & $2,4 \%$ & BA & $1,9 \%$ & CE & $1,7 \%$ & RO & $1,4 \%$ & RO & $1,8 \%$ \\
\hline Soma & $89,6 \%$ & & $85,7 \%$ & & $90,4 \%$ & & $91,5 \%$ & & $91,2 \%$ & & $92,2 \%$ & & $90,7 \%$ \\
\hline Regiões & & & & & & & & & & & & & \\
\hline SE & $47,6 \%$ & & $46,0 \%$ & & $50,2 \%$ & & $54,3 \%$ & & $53,5 \%$ & & $52,7 \%$ & & $52,9 \%$ \\
\hline S & $31,2 \%$ & & $29,7 \%$ & & $30,0 \%$ & & $29,3 \%$ & & $29,9 \%$ & & $31,3 \%$ & & $29,2 \%$ \\
\hline N, NE, CO & $21,2 \%$ & & $24,3 \%$ & & $19,8 \%$ & & $16,4 \%$ & & $16,6 \%$ & & $16,0 \%$ & & $17,9 \%$ \\
\hline
\end{tabular}

Fonte: Elaboração própria com base nos dados do MDIC (2017)

Em segundo e terceiro lugares aparecem, durante todo o período, os estados do Rio Grande do Sul e Paraná (Gráfico 5). 
Gráfico 5 - Principais Estados sede das MPE exportadoras.

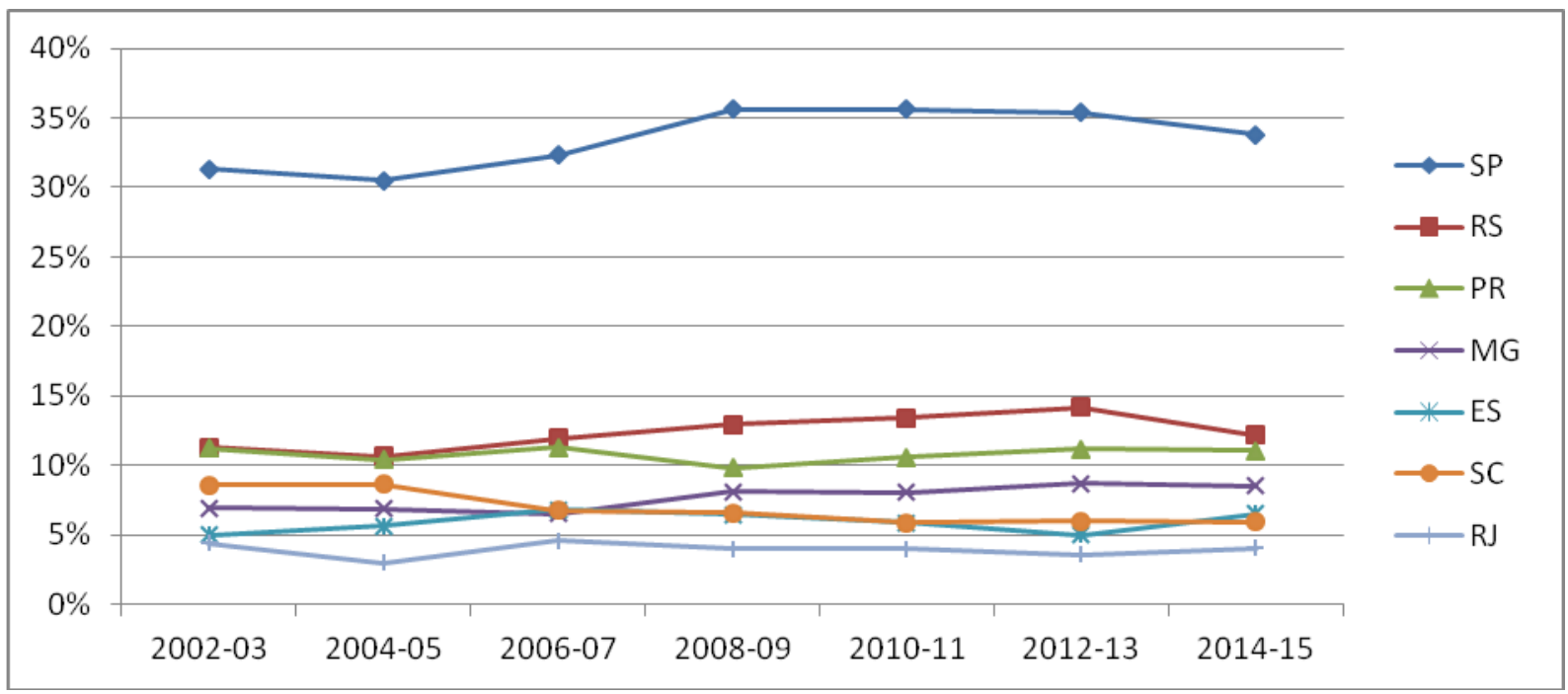

Fonte: Elaboração própria com base nos dados do MDIC (2017)

\section{CONSIDERAÇÕES FINAIS}

A questão da internacionalização de MPE tem sido debatida em vários âmbitos nacionais e internacionais. Como já citado, o objetivo deste trabalho foi explorar os dados de Comércio Exterior do Ministério da Indústria, Comércio Exterior e Serviços em busca de insights que ajudem a entender o momento atual com base na história recente deste assunto.

A primeira conclusão que se pode considerar a partir do presente trabalho, é que as recentes políticas de incentivo à exportação pelas MPE, aparentemente, não têm gerado os resultados esperados. Mesmo com grande aumento no total exportado pelo país, as exportações das MPE não tiveram o mesmo desempenho. Desde 2008-2009, os valores de exportações das MPE oscilaram entre US\$ 1,7 e US\$ 2,0 bilhões, não chegando ao patamar do biênio anterior, que foi próximo a US\$ 2,7 bilhões anuais. Ou seja, enquanto as exportações totais do país cresciam, as das MPE encolhiam. Deve-se reconhecer que no último biênio analisado, apesar da queda das exportações totais do Brasil, houve aumento nas exportações das MPE, que ficou pouco abaixo de $1 \%$ do total exportado. Entretanto este percentual não é nem a metade do que foi entre 2002 e 2005.

Em relação ao destino das exportações, a China tem sido o grande comprador de produtos brasileiros, tendo, ao longo de período estudado, crescido de forma vigorosa e assumindo a primeira posição desde o biênio 2010-2011. Já em relação às exportações das MPE, os EUA sempre mantiveram a primeira posição, embora tenha diminuído percentualmente sua participação ao longo do período. Nesse sentido, a queda no valor exportado do biênio 2006-2007 para o biênio 2008-2009 coincide com a diminuição das exportações para os EUA, evidenciando a importância desse país para as exportações de MPE brasileiras. Outro fator que chama a atenção é o aumento do número de países da América do Sul entre os dez principais destinos de exportações de MPE.

Em relação aos estados que sediam as empresas exportadoras, ao longo do período pesquisado, houve mudanças importantes. Enquanto no total de exportações a participação de empresas sediadas no estado de São Paulo vem diminuindo com o tempo, passando de 37,2\% em 2002-2003 para 26,3\% em 2014-2015, nas exportações das MPE a participação desse estado estabilizou-se na faixa de 35\%, apesar 
de no último biênio ter caído para 33,8\%. Outro dado relevante é a participação de empresas sediadas na região sul, principalmente nos estados do Rio Grande do Sul e Paraná, que figuraram durante todo o período pesquisado na segunda e terceira posições. Na região Sudeste, conforme já citado, surpreende o estado do Rio de Janeiro, que com toda a sua pujança econômica e cultural, figura entre o sétimo e oitavo lugares nas exportações de MPE.

O presente trabalho buscou explorar os dados acerca das exportações brasileiras, principalmente em relação às MPE. Evidenciou-se que tem havido, ao longo dos anos, diminuição da participação da MPE nas exportações brasileiras. Nesse sentido, a presente pesquisa pode contribuir como um alerta para que tal situação seja melhor estudada, com o objetivo de auxiliar o aumento das exportações pelas MPE. Sugerem-se, para isso, estudos mais focados nos motivos que geraram o tal desempenho. Outro fator a ser estudado é o desempenho de exportações de MPE de países da América do Sul, que ajudaria a avaliar a performance das MPE brasileiras.

\section{REFERÊNCIAS}

ALCÂNTARA, J. N.et al. Fatores Determinantes da Utilização de Programas de Apoio à Exportação: Evidências de PME's do Estado de Minas Gerais. Revista de Administração FACES Journal, v. 14, n. 3, p. 114-132, 2015.

AMAL, M.; FREITAG FILHO, A. R.; MIRANDA, C. M. S. Algumas evidências sobre o papel das redes de relacionamento e empreendedorismo na internacionalização das pequenas e médias empresas. Revista de Administração FACES Journal, v. 7, n. 1, p. 63-80, 2008.

ARAUJO, J. B. de; ZILBER, S. N. Adoção de E-Business e mudanças no modelo de negócio: inovação organizacional em pequenas empresas dos setores de comércio e serviços. Gestão \& Produção, São Carlos, v. 20, n. 1, p. 147-161, mar. 2013.

ARBIX, G.; SALERNO, M. S.; DE NEGRI, J. A. O impacto da internacionalização com foco na inovação tecnológica sobre as exportações das firmas brasileiras. DADOS - Revista de Ciências Sociais, v. 48, n. 1, p. 395-442, 2005.

BARNEY, J. B. Gaining and Sustaining Competitive Advantage. $4^{\text {th }}$ ed. New Delhi: PHI Learning, 2011.

BRASIL. Lei no 10.933, de 11 de agosto de 2004. Dispõe sobre o Plano Plurianual para o período 2004/2007. Diário Oficial da União, Brasília, 12 ago. 2004.

CAHEN, F. R.; LAHIRI, S.; BORINI, F. M. Managerial perceptions of barriers to internationalization: An examination of Brazil's new technology-based firms. Journal of Business Research, v. 69, n. 6, p. 1973$1979,2016$.

CRUZ, B. de P. A.; ZOUAIN, D. M. Atuação de consórcios de exportação brasileiros no segmento de moda praia. Revista de Administração Mackenzie, São Paulo, v. 9, n. 2, p. 11-30, 2008.

ELIASSON, K.; HANSSON, P.; LINDVERT, M. Do firms learn by exporting or learn to export? Evidence from small and medium-sized enterprises. Small Business Economics, v. 39, n. 2, p. 453-472, 2012.

ESTEVES, G.; NOHARA, J. J. Fatores Críticos à Estabilidade das Alianças Estratégicas das Micro e Pequenas Empresas. RAI - Revista de Administração e Inovação, v. 8, n. 3, p. 182-204, 2011. 
FLORIANI, D. E.; FLEURY, M. T. O Efeito do Grau de Internacionalização nas Competências Internacionais e no Desempenho Financeiro da PME Brasileira. RAC - Revista de Administração Contemporânea, Rio de Janeiro, v. 16, n. 3, p. 438-458, 2012.

GIL, A. C. Métodos e Técnicas de Pesquisa Social. 6. ed. São Paulo: Atlas, 2008.

GUIMARÃES, A. M.; SACOMANO NETO, M.; VICARI, F. M. Análise da inserção de pequenas e médias empresas no mercado internacional: casos de insucesso. Revista da Micro e Pequena Empresa, v. 6, n. 3, p. 133-149, 2012.

INFANTE, C. E. D. de C.; MENDONCA, F. M. de; VALLE, R. de A. B. do. Análise de robustez com o método Electre III: o caso da região de Campo das Vertentes em Minas Gerais. Gestão \& Produção, São Carlos, v. 21, n. 2, p. 245-255, jun. 2014.

KISS, A. N.; FERNHABER, S.; MCDOUGALL-COVIN, P. P. S. Innovation, and Export Intensity: Implications for Small-and Medium-Sized Enterprises. Entrepreneurship Theory and Practice, 2017.

LA ROVERE, R. L. Perspectivas das micro, pequenas e médias empresas no Brasil. Revista de Economia Contemporânea, v. 34, p. 137-154, 2001.

LAVAL, C. H.; CASTRO, S. D. Lei Geral da Micro e da Pequena Empresa em Goiás. Estudos, Goiânia, v. 40, n. 3, p. 275-285, 2013.

LUNARDI, G. L.; DOLCI, P. C.; MAÇADA, A. C. G. Adoção de tecnologia de informação e seu impacto no desempenho organizacional: um estudo realizado com micro e pequenas empresas. Revista de Administração, São Paulo, v. 45, n. 1, p. 05-17, jan./fev./mar. 2010.

MDIC - Ministério da Indústria, Comércio Exterior e Serviços. Disponível em < http://www.mdic.gov.br/index.php/comercio-exterior/estatisticas-de-comercio-exterior/ >. Acesso em 07/07/2017.

MICHEL, M. H. Metodologia e pesquisa científica em ciências sociais: um guia prático para acompanhamento da disciplina e elaboração de trabalhos monográficos. 2. ed. São Paulo: Atlas, 2009.

MOREIRA, B. C. M.; COSTA, D. F.; CARPENEDO, E. B. Políticas de desenvolvimento para micro e pequenas empresas: Marcos, limites e desafios de uma política industrial articulada no Brasil. RDE Revista de Desenvolvimento Econômico, v. 16, n. 30, 2014.

NARETTO, N.; BOTELHO, M. dos R.; MENDONÇA, M. A Trajetória das Políticas Públicas para Pequenas e Médias Empresas no Brasil: do Apoio Individual ao Apoio a empresas articuladas em arranjos Produtivos Locais. Brasília. Planejamento e Políticas Públicas (IPEA), n. 27, 2004.

NOGUEIRA, M. O. O panorama das políticas públicas federais brasileiras voltadas para as empresas de pequeno porte. Texto para Discussão no. 2217, Instituto de Pesquisa Econômica Aplicada (IPEA), 2016.

PELISSARI, A. S.; GONZALES, I. V. de F. P.; VANALLE, R. M. Competências gerenciais: um estudo em pequenas empresas de confecções. REAd - Revista Eletrônica de Administração, v. 17, n. 1, p. 149180, 2011.

RUZZIER, M.; HISRICH, R. D.; ANTONCIC, B. SME internationalization research: past, present, and future. Journal of small business and enterprise development, v. 13, n. 4, p. 476-497, 2006.

SANTOS, L. L. da S.; ALVES, R. C.; ALMEIDA, K. N. T. de. Formação de estratégia nas micro e pequenas empresas: um estudo no centro-oeste mineiro. RAE-Revista de Administração de Empresas, São Paulo, v. 47, n. 4, p. 59-73, Dez. 2007. 
SARFATI, G. Estágios de desenvolvimento econômico e políticas públicas de empreendedorismo e de micro, pequenas e médias empresas (MPMEs) em perspectiva comparada: os casos do Brasil, do Canadá, do Chile, da Irlanda e da Itália. Revista de Administração Pública, v. 47, n. 1, p. 25-48, 2013.

SEBRAE. Participação das Micro e Pequenas Empresas na Economia Brasileira. Brasília: SEBRAE, 2014.

SOUSA, C. M. P.; LENGLER, J. F. B.; MARTÍNEZ-LÓPEZ, F. J. Testing for linear and quadratic effects between price adaptation and export performance: the impact of values and perceptions. Journal of Small Business Management, v. 52, n. 3, p. 501-520, 2014.

SOUSA, G. de F.; BOTELHO, M. dos R. A. Política Industrial e Evolução das Exportações das Empresas de Pequeno Porte Brasileiras nos Anos 2000. Planejamento e Políticas Públicas, n. 45, 2015.

SOUZA, M. C. de A. F. de; MAZZALI, L. Conceito e espaço da pequena empresa na estrutura industrial: heterogeneidade e formas de inserção. Gestão \& Produção, São Carlos, v. 15, n. 3, p. 591-603, dez. 2008.

ZHANG, X.; MA, X.; WANG, Y.; LI, X.; HUO, D. What drives the internationalization of Chinese SMEs? The joint effects of international entrepreneurship characteristics, network ties, and firm ownership. International Business Review, v. 25, n. 2, p. 522-534, 2016. 